\title{
Dose Effect of Phytosanitary Irradiation on the Postharvest Quality of Cut Flowers
}

\author{
Song Kwon ${ }^{1}$, Hye Jin Kwon², Ju Hyun Ryu³ , and Yu Ri Kim ${ }^{4}$ \\ ${ }^{1}$ Research engineer, Research Institute of Agriculture and Life Science, Seoul National University, Seoul 08826, Korea \\ ${ }^{2}$ Associate professor, Division of Smart Horticulture, Yonam College, Cheonan 31005, Korea \\ ${ }^{3}$ Assistant director, Siheung City Agriculture Technology Center, Siheung City Hall, Siheung 14998, Korea \\ ${ }^{4}$ Chief researcher, EB Tech Co., Ltd., Daejeon 34028, Korea
}

\section{ABSTRACT}

The present study was conducted to determine the effects of electron beam irradiation on the postharvest quality of cut flowers. Cut flowers were irradiated with electron beam at 100, 200, 400, 600, 800, 1,000, and 2,000 Gy with a $10 \mathrm{MeV}$ linear electron beam accelerator to evaluate their irradiation tolerance. Postharvest quality was determined by monitoring fresh weight loss, flower longevity, flower diameter, flowering rate, visual quality of flowers and leaves, and chlorophyll content. Cut flowers showed a radiation-induced damage with increasing the irradiation dose. Flower longevity and fresh weight of cut flowers decreased when the irradiation dose was increased. Flower bud opening was also inhibited in a dose-dependent manner. The effective irradiation doses for $10 \%$ reduction of postharvest quality $\left(E D_{10}\right)$ values were 144.4, 451.6, and 841.2 Gy in the 'Medusa' lily, 'Montezuma' carnation, and 'Rosina White' eustoma, respectively. Although tolerance of cut flowers to electron beam irradiation vary according to species, cultivars, or maturity stage conditions, it is conceivable that 'Montezuma' carnation and 'Rosina White' eustoma could be tolerated and maintained overall postharvest quality up to $400 \mathrm{~Gy}$, the generic irradiation dose approved by the Animal and Plant Health Inspection Service (APHIS) and the International Plant Protection Convention (IPPC) for postharvest phytosanitary treatments.

Keywords: electron beam irradiation, flower export, irradiation tolerance, quality evaluation, quarantine

\section{Introduction}

Irradiation as a phytosanitary treatment is increasing in commercial use because it has some advantages over other treatments, such as applicability to packed commodities and broad tolerance by fresh commodities (Heather and Hallman, 2008). Unlike other phytosanitary treatments, irradiation does not need to kill the target pests immediately to provide quarantine security, therefore live pests may occur with the exported commodity. The objective of phyto- sanitary irradiation is to prevent reproduction of pests, thus prevention of adult emergence, induction of adult sterility, or F1 sterility should be required for radiation treatment (Follett, 2009).

International Standards for Phytosanitary Measures (ISPM) No. 18 provides technical guidance on the specific procedures for the application of ionizing radiation as a phytosanitary treatment for regulated pests or articles (Food and Agriculture Organization of the United Nations, 2003). Moreover, irradiation has been very amenable to generic

\footnotetext{
This work was supported by Korea Institute of Planning and Evaluation for Technology in Food, Agriculture, and Forestry (IPET) through the Export Promotion Technology Development Program (No. 109061-3) funded by the Ministry of Agriculture, Food and Rural Affairs (MAFRA), and the National Research Foundation of Korea (NRF) and the Center for Women in Science, Engineering and Technology (WISET) Grant funded by the Ministry of Science and ICT under the program for Returner into R\&D (WISET-2017-592).

Received: April, 9, 2020, Revised: April, 14, 2020, Accepted: April 16, 2020

First author: Song Kwon, freesia77@empal.com, (1) https://orcid.org/0000-0002-3190-7217

*Corresponding author: Yu Ri Kim, yrkim@eb-tech.com, (D) https://orcid.org/0000-0003-1164-8542
} 
doses, one dose serves for a group of pests and commodities although not all have been tested for efficacy (Follett, 2009; Hallman, 2012). Currently, two broad generic treatments, 150 Gy for all Tephritidae and 400 Gy for all Insecta except pupal and adult Lepidoptera, are approved for use on imports to the United States (Animal and Plant Health Inspection Service, 2014).

Irradiation has been documented to be effective against various quarantine pests of cut flowers. Preliminary tests on armyworm, Spodoptera litura, suggested that the fecundity of adults developed from irradiated pupae is entirely inhibited at 150 Gy (Yun et al., 2014). Koo et al. (2012) also reported that a minimum dose of 150 Gy should be sufficient for female sterilization of American serpentine leafminer fly, Liriomyza trifolii. Moon et al. (2010) suggested that a radiation dose of $100 \mathrm{~Gy}$ applied to pupae of diamondback moth, Plutella xylostella, might be sufficient to sterilize adults and stop egg hatch. When Bemisia tabaci, Myzus persicae, and Tetranychus urticae adults were irradiated with $100 \mathrm{~Gy}$, fecundity decreased and egg hatch was inhibited.

Postharvest quality studies should be done on commodities in conjunction with pest disinfestation testing to ensure that treatments do not cause unacceptable injury to the commodity. Flowers can also be damaged by irradiation, depending on the tolerance of flowers to irradiation as well as the irradiation dose (Hayashi et al., 1998). Therefore, the appropriate dose level for electron beam irradiation is needed to be determined for cut flowers without detriment to their quality.

Hayashi et al. (1998) reported that carnation, alstromeria, gladiolus, tulip, statice, stock, dendrobium, prairie gentian, oncidium, campanula, gloriosa, fern, gypsophila, freesia, lobelia, triteleia, and gerbera were tolerant to electron beams at 400-600 Gy, while chrysanthemum, rose, lily, calla, anthurium, sweet pea, and iris were intolerant. Kikuchi (2003) also reported that the dose of 300 Gy was considered as the minimum value for tolerance of the flowers to $\gamma$ - and electron beam irradiation. Lilium speciosum, Alpinia purpurata, and Lisianthus sp. were tolerant to both kinds of radiation. However, previous investigations have been limited by the lack of explanation about cultivar, harvest stage, conditioning methods, test room conditions, and flower longevity terminating symptoms. Few studies have been performed to prove dose-response relationship between irradiation dose and postharvest quality of cut flowers for sufficiently accurate dose estimation.

The present study was conducted to examine the effect of electron beam irradiation on the postharvest quality of cut flowers and to verify the tolerance to electron beam irradiation.

\section{Research Methods}

\section{Plant materials}

Cut lily flowers 'Medusa' (Lilium Oriental hybrid 'Medusa') were used for experiments. 'Medusa' lilies were obtained from Guidoon Flower Export Complex (Inje, Korea). Flowers were at the commercial harvest stage, with the largest bud showing color. Cut carnation flowers 'Montezuma' (Dianthus caryophyllus 'Montezuma') were purchased from a local wholesaler in Seoul, Korea. Flowers were at the commercial harvest stage, paint brush stage. Cut eustoma flowers 'Rosina White' (Eustoma grandiflorum 'Rosina White') were purchased from a local wholesaler in Seoul, Korea. Flowers were at the commercial harvest stage, with the largest bud showing color.

\section{Electron beam irradiation}

Electron beam irradiation was conducted in EB-Tech Co., Ltd. (Daejeon, Korea) using a high energy linear accelerator (UEL V10-10S, $10 \mathrm{MeV}$ ). Cut flowers were treated with doses of 100, 200, 400, 600, 800, 1,000, and 2,000 Gy. Target doses were monitored by dosimetry with a radiochromic film dosimeter (GAF3002DS, GEX Corp., Centennial, CO, USA; ISO/ASTM51275:2004[E]).

\section{Quality evaluation}

After irradiation, stems were recut to $30 \mathrm{~cm}$ for eustoma flowers, and to $40 \mathrm{~cm}$ for lily and carnation flowers. After re-cutting, stems were placed in distilled water and then kept in an air-conditioned room with a $12 \mathrm{~h}$ light cycle at $23 \pm 1{ }^{\circ} \mathrm{C}$, relative humidity of $60 \pm 10 \%$, and a leaf level 
photosynthetic photon flux density at $140 \mu \mathrm{mol} \cdot \mathrm{m}^{-2} \cdot \mathrm{s}^{-1}$ provided by cool white fluorescent lamps. Postharvest quality was determined by monitoring fresh weight loss, flower longevity, flower diameter, visual quality of leaves, and chlorophyll content. Flower longevity was determined with senescence symptoms according to the general criteria. A flower was considered senesced when the lily flower has wilted or dropped, the carnation flower has shrunk or shown brown discoloration, and more than $50 \%$ of the eustoma flowers have wilted. Flower diameter was measured at the widest point by using a digital caliper (ABS Digimatic Caliper, Mitutoyo Co., Ltd., Tsukuba, Japan). To evaluate aesthetic quality, an index of visual quality of leaves was applied. The scale ranged from 1 (very poor) to 5 (excellent) based on the amount of discoloration and necrosis. The chlorophyll content was measured using a SPAD-502 meter (Konica-Minolta, Tokyo, Japan). The treatments were replicated five times.

\section{Determining dose effects}

Dose effects were determined by dose-response relationship between irradiation dose and postharvest quality. Postharvest quality loss was measured using parameters, such as flower longevity, flower diameter, flowering rate, visual quality of leaves, and chlorophyll content. Dose effects were estimated using the following equation: Dose effects $(\%)=\mathrm{B} / \mathrm{A} \times 100$, where $\mathrm{A}=$ parameter value of non-irradiated flowers and $\mathrm{B}=$ parameter value of irradiated flowers. Nonlinear regression was conducted to determine the dose-effect by Sigma Plot, version 10.0 (SPSS Science, Chicago, IL, USA). The four-parameter logistic sigmoidal curves were used to determine the effective irradiation doses for $10 \%$ reduction of postharvest quality $\left(\mathrm{ED}_{10}\right)$ and was calculated as $\mathrm{y}=\mathrm{y} 0+\mathrm{a} /\left[1+(\mathrm{x} / \mathrm{x} 0)^{\mathrm{b}}\right]$, where $\mathrm{x}$ and $\mathrm{y}$ are variables, $\mathrm{x} 0, \mathrm{y} 0, \mathrm{a}$, and $\mathrm{b}$ are parameters.

\section{Statistical Analysis}

Statistical analysis was performed using SAS software, version 9.2 (SAS Inst., Cary, NC, USA). Differences among the group means were analyzed using analysis of variance (ANOVA) and Duncan's multiple range test at 5\% level.

\section{Results and Discussion}

\section{Quality evaluation}

The effect of electron beam irradiation on fresh weight loss of cut flowers was examined. 'Medusa' lily in the control group bloomed and its fresh weight continued to increase to $125.9 \%$, but started to slowly decrease after 4 days, showing a higher fresh weight than that of the irradiated flowers (Fig. 1A). The fresh weight of 'Medusa' lily decreased as the irradiation dose increased. Flowers irradiated at 2,000 Gy lost fresh weight faster, and this loss decreased flower longevity. In 'Montezuma' carnation and

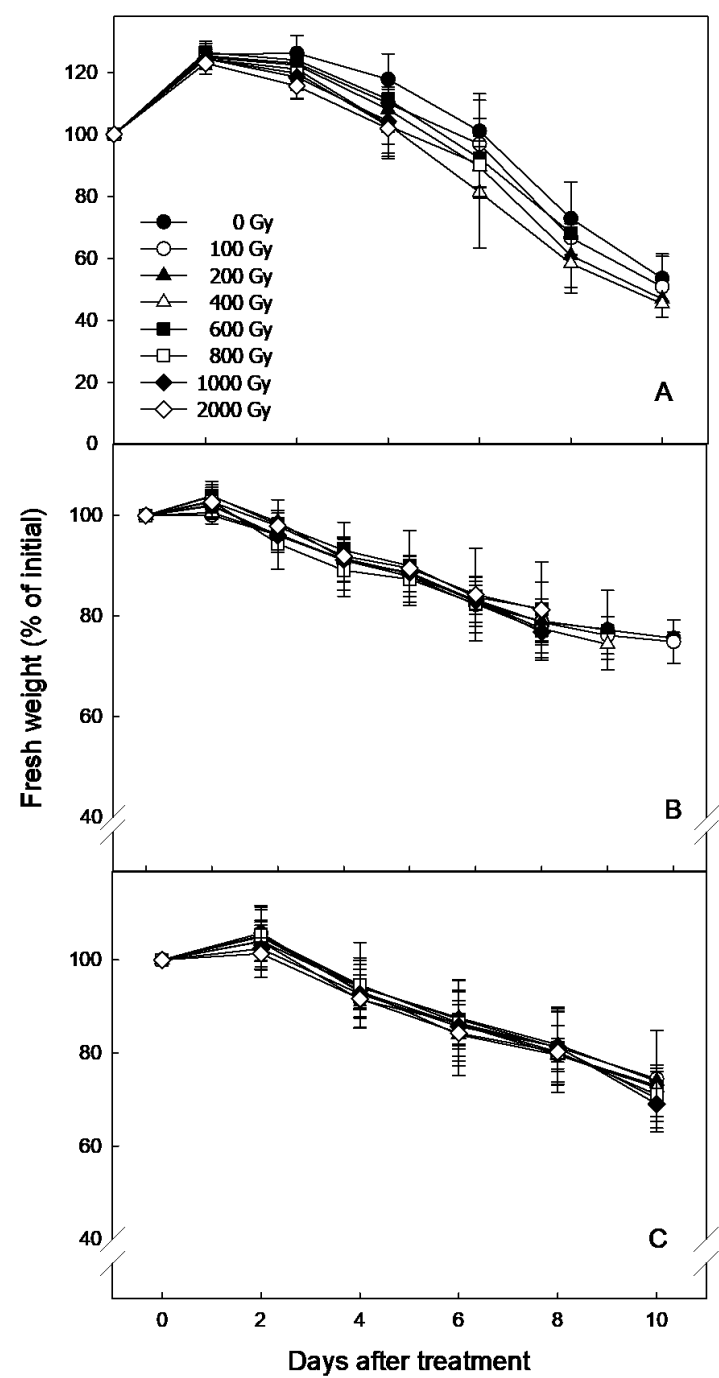

Fig. 1. Effects of electron beam irradiation on fresh weight of 'Medusa' lily (A), 'Montezuma' carnation (B), and 'Rosina White' eustoma (C) flowers. Data are the means \pm SD from five replications. 
Table 1. Effects of electron beam irradiation on the postharvest quality of cut flowers

\begin{tabular}{|c|c|c|c|c|c|c|c|c|c|c|}
\hline \multirow[t]{2}{*}{$\begin{array}{l}\text { Irradiation } \\
\text { dose (Gy) }\end{array}$} & \multicolumn{3}{|c|}{$\begin{array}{c}\text { Flower longevity } \\
\text { (day) }\end{array}$} & \multicolumn{3}{|c|}{$\begin{array}{l}\text { Flower diameter } \\
\qquad(\mathrm{mm})\end{array}$} & \multicolumn{2}{|c|}{$\begin{array}{c}\text { Visual quality } \\
\text { of leaves } \\
(1-5)^{\mathrm{z}}\end{array}$} & \multirow{2}{*}{$\begin{array}{c}\text { Chlorophyll } \\
\text { content }(\mathrm{SPAD} \\
\text { readout })^{\mathrm{y}}\end{array}$} & \multirow{2}{*}{$\begin{array}{c}\begin{array}{c}\text { Flowering } \\
\text { rate } \\
(\%)^{\mathrm{x}}\end{array} \\
\text { Eustoma }\end{array}$} \\
\hline & Lily & Carnation & Eustoma & Lily & Carnation & Eustoma & Lily & Carnation & & \\
\hline 0 & $12.0 \mathrm{a}^{\mathrm{w}}$ & $12.6 \mathrm{ab}$ & $9.0 \mathrm{a}$ & $140.3 \mathrm{a}$ & $76.8 \mathrm{a}$ & $56.0 \mathrm{a}$ & $5.0 \mathrm{a}$ & $3.2 \mathrm{a}$ & $57.9 \mathrm{a}$ & $100.0 \mathrm{a}$ \\
\hline 100 & $11.8 \mathrm{a}$ & $13.8 \mathrm{a}$ & $9.2 \mathrm{a}$ & $128.2 \mathrm{a}$ & $76.6 \mathrm{a}$ & $55.1 \mathrm{a}$ & $5.0 \mathrm{a}$ & $3.7 \mathrm{a}$ & $56.7 \mathrm{a}$ & $95.8 \mathrm{ab}$ \\
\hline 200 & $11.4 \mathrm{a}$ & $11.8 \mathrm{abc}$ & $9.2 \mathrm{a}$ & $109.7 \mathrm{~b}$ & $75.2 \mathrm{ab}$ & $56.2 \mathrm{a}$ & $4.8 \mathrm{a}$ & $3.3 \mathrm{a}$ & $56.5 \mathrm{a}$ & $95.8 \mathrm{ab}$ \\
\hline 400 & $10.0 \mathrm{~b}$ & $12.0 \mathrm{abc}$ & $8.8 \mathrm{a}$ & $90.9 \mathrm{c}$ & $77.4 \mathrm{a}$ & $56.9 \mathrm{a}$ & $4.0 \mathrm{~b}$ & $3.0 \mathrm{ab}$ & $52.7 \mathrm{ab}$ & $95.8 \mathrm{ab}$ \\
\hline 600 & $7.6 \mathrm{c}$ & $10.4 \mathrm{bc}$ & $8.7 \mathrm{ab}$ & $43.0 \mathrm{~d}$ & $74.3 \mathrm{abc}$ & $55.8 \mathrm{a}$ & $3.4 \mathrm{c}$ & $3.0 \mathrm{ab}$ & $50.3 \mathrm{bc}$ & $95.8 \mathrm{ab}$ \\
\hline 800 & $6.4 \mathrm{~cd}$ & $9.6 \mathrm{c}$ & $8.3 \mathrm{ab}$ & $38.5 \mathrm{~d}$ & $70.5 \mathrm{bc}$ & $56.2 \mathrm{a}$ & $2.6 \mathrm{~d}$ & $2.2 \mathrm{bc}$ & $49.4 \mathrm{bc}$ & $91.7 \mathrm{ab}$ \\
\hline 1000 & $5.8 \mathrm{~d}$ & $9.4 \mathrm{c}$ & $7.7 \mathrm{~b}$ & $36.1 \mathrm{~d}$ & $70.2 \mathrm{bc}$ & $53.9 \mathrm{a}$ & $2.0 \mathrm{e}$ & $2.0 \mathrm{c}$ & $48.8 \mathrm{bc}$ & $87.5 \mathrm{ab}$ \\
\hline 2000 & $4.0 \mathrm{e}$ & $9.2 \mathrm{e}$ & $7.7 \mathrm{~b}$ & $32.0 \mathrm{~d}$ & $68.9 \mathrm{c}$ & $53.4 \mathrm{a}$ & $2.0 \mathrm{e}$ & $2.2 \mathrm{bc}$ & $46.6 \mathrm{c}$ & $84.2 \mathrm{~b}$ \\
\hline Significance & $* * * *$ & $*$ & $*$ & $* * * *$ & $*$ & NS & $* * * *$ & $* *$ & $* * *$ & NS \\
\hline
\end{tabular}

${ }^{\mathrm{z}}$ Based on a scale of 1 to 5 , measured at 6 days after treatment. 1 = very poor quality (not acceptable, severe leaf necrosis or yellowing, not marketable); 2 = poor quality (not acceptable, large areas of necrosis or yellowing, poor form, not marketable); $3=$ fair quality (marginally acceptable, somewhat desirable form and color); 4 = good quality (very acceptable, nice color without yellowing, good form, marketable); $5=$ excellent.

${ }^{\mathrm{y}}$ Leaf chlorophyll content at 6 days after treatment.

${ }^{\mathrm{x}}$ Ratio of fully open flowers to the total number of initial flower buds per bunch.

"Duncan's multiple range test within columns, $p=.05$.

${ }^{\mathrm{NS}}$ Non-significant, ${ }^{*} p<.05,{ }^{* *} p<.01,{ }^{* * *} p<.001,{ }^{* * * *} p<.0001$.

'Rosina White' eustoma, the fresh weight change of irradiated flowers showed similar pattern to that of non-irradiated controls (Fig. 1B, 1C). Flower longevity was measured to assess their postharvest quality after irradiation (Table 1). Flower longevity of 'Medusa' lily was maintained by irradiation up to $200 \mathrm{~Gy}$. In 'Montezuma' carnation, there were no significant differences in flower longevity between the non-irradiated controls and the irradiated samples at $\leq 600$ Gy. In 'Rosina White' eustoma, flowers irradiated at $\leq 800$ Gy maintained their flower longevity. The success of irradiation as a phytosanitary treatment depends not only on its capacity to kill or neutralize target insects but also on the tolerance of plants to ionizing energy (Ornelas-Paz et al., 2017). The present study described the response of several cut flowers to electron beam irradiation. The results are in agreement with those of Kim et al. (2014), who found fresh weight loss of 'Siberia', 'Le reve', and 'Sorbonne' lilies irradiated with $\gamma$-ray at 200 Gy. They also reported that cut lilies were severely dried by $\gamma$-irradiation compared to the non-irradiated control, which may be caused by the lower ability to absorb water.

Flower diameter of 'Medusa' lily after irradiation was measured, and the results showed that the maximum flower diameter significantly decreased with increasing the irradiation dose (Table 1). Corolla growth and opening were inhibited in 'Medusa' irradiated at $\geq 200$ Gy (Fig. 2A). Flower diameter of 'Montezuma' carnation was maintained by irradiation up to 600 Gy (Fig. 2B). In 'Rosina White' eustoma, there were no significant differences in the flower diameter between the non-irradiated control and the irradiated samples (Fig. 2C). The results indicated that irradiation did not affect the flower opening of 'Montezuma' carnation and 'Rosina White' eustoma as flower diameter did not decrease with increasing the irradiation dose (Fig. 2B). The results of the present study correspond well with those found in the earlier experimental studies in Lilium speciosum (Kikuchi, 2003) and daylily (Yang et al., 2002). Chang et al. (1997) also reported that 'Royalty' roses irradiated at $\geq 250$ Gy had a smaller diameter than control roses. The results of this study suggest that flower opening inhibition by irradiation can be applicable as a potential indicator of irradiation sensitivity.

Visual quality of leaves in 'Medusa' lily decreased over time, and that of the irradiated samples $\leq 200$ Gy was 
(A)

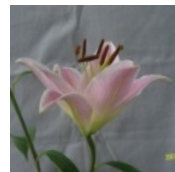

(B)

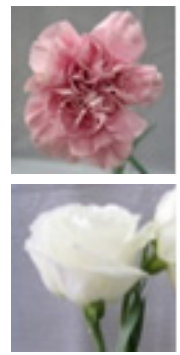

0
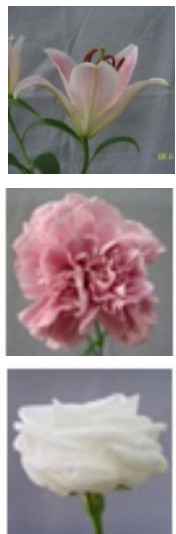

100

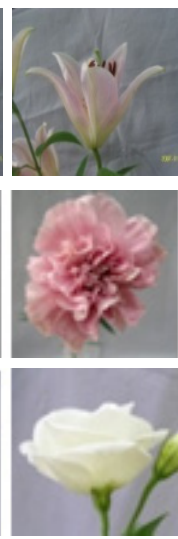

200

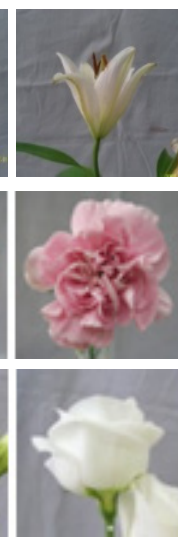

400
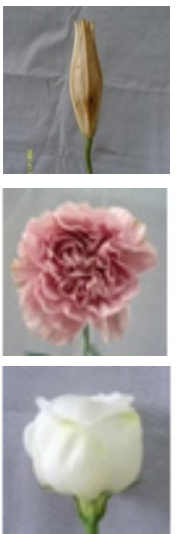

600
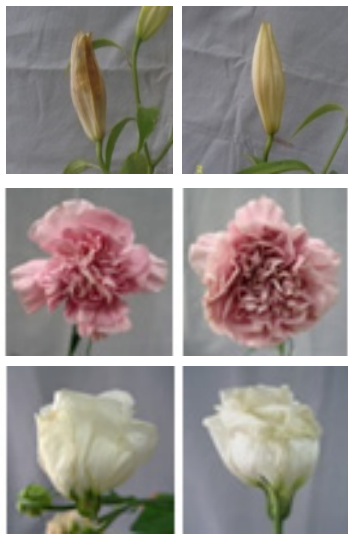

800

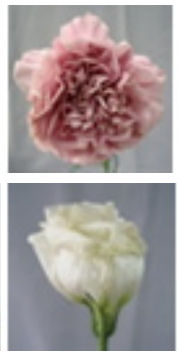

1000
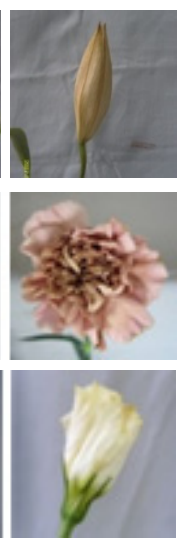

2000

Irradiation dose (Gy)

Fig. 2. Appearance of 'Medusa' lily (A), 'Montezuma' carnation (B), and 'Rosina White' eustoma (C) flowers at 6, 10, 8 days, respectively, after electron beam irradiation at various doses.

similar to that of the control (Table 1). In 'Montezuma' carnation, there were no significant differences in visual quality of leaves between the non-irradiated and irradiated samples at $\leq 600$ Gy. Hayashi and Todoriki (1996) reported that 'Seishu' chrysanthemums irradiated with $\gamma$-rays at $750 \mathrm{~Gy}$ observed a foliage yellowing.

Chlorophyll content in 'Medusa' lily was maintained high by irradiation up to $400 \mathrm{~Gy}$, and started to decrease with increasing the irradiation dose (Table 1). It is inferred that the major impact of irradiation on cut flowers is loss of chlorophyll content concomitant with loss of visual quality in leaves. Van Doorn and Han (2011) reported that vase life of cut lily flowers is often determined by the life of leaves rather than that of flower perianths. These results are in close agreement with those of Kim et al. (2014), who found loss of chlorophyll content in 'Siberia' and 'Sorbonne' lilies irradiated with $\gamma$-ray at $200 \mathrm{~Gy}$. In 'Rosina White' eustoma, there were no significant differences in flowering rate between the control and the irradiated samples (Table 1).

\section{Determining dose effects}

The present study was carried out to prove dose-response relationship between irradiation dose and postharvest quality of cut flowers for sufficiently accurate dose estimation. In 'Medusa' lily, the effective irradiation doses for $10 \%$ reduction of postharvest quality $\left(\mathrm{ED}_{10}\right)$ were $289.4,144.4$, 315.7, and 462.7 Gy in flower longevity, flower diameter, visual quality of leaves, and chlorophyll content, respectively (Fig. 3). The results of this study suggest that irradiation dose not less than 144.4 Gy can cause a detrimental change on the postharvest quality of 'Medusa' lily, such as flower opening inhibition.

In 'Montezuma' carnation, $\mathrm{ED}_{10}$ values were 451.6 and $622.7 \mathrm{~Gy}$ in flower longevity and visual quality of leaves, respectively (Fig. 4). The results of the present study indicate that irradiation dose not less than 451.6 Gy can cause a detrimental change on the postharvest quality of 'Montezuma' carnation, such as shortening of flower longevity.

In 'Rosina White' eustoma, $\mathrm{ED}_{10}$ values were 841.2 and 879.7 Gy in flower longevity and flowering rate, respectively (Fig. 5). The results of this study suggest that 'Rosina White' eustoma with electron beam irradiation up to 841.2 Gy maintains the overall postharvest quality with the exception of flower longevity.

Although tolerance of cut flowers to electron beam irradiation vary according to species, cultivars, or maturity stage conditions (Hayashi et al., 1998; Kikuchi, 2003; Sangwanangkul et al., 2008), it is conceivable that 'Montezuma' carnation and 'Rosina White' eustoma could be tolerant to electron beam irradiation at $400 \mathrm{~Gy}$, the generic irradiation dose approved by the Animal and Plant Health Inspection Service (APHIS) and the International 


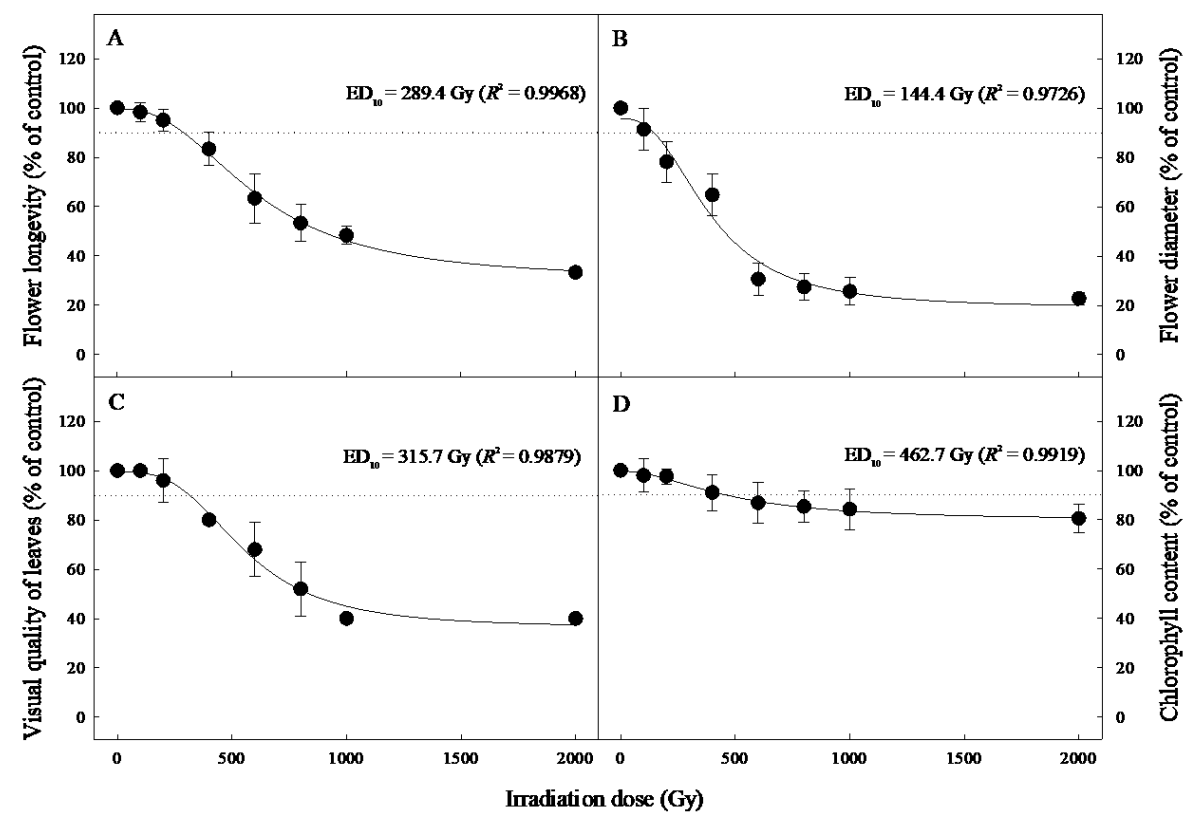

Fig. 3. Dose response curves for electron beam irradiation effects on flower longevity (A), flower diameter (B), visual quality of leaves (C), and chlorophyll content (D) in 'Medusa' lilies. Data are the means \pm SD from five replications.

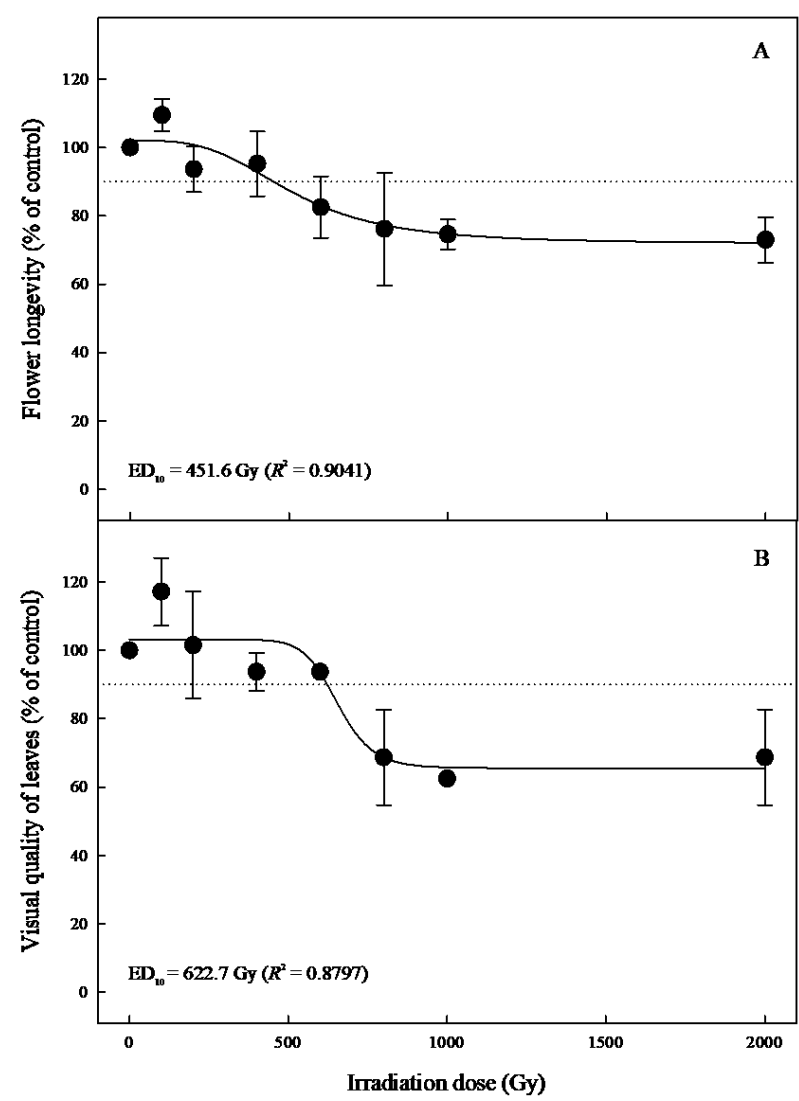

Fig. 4. Dose response curves for electron beam irradiation effects on flower longevity $(A)$ and visual quality of leaves (B) in 'Montezuma' carnations. Data are the means \pm SD from five replications.

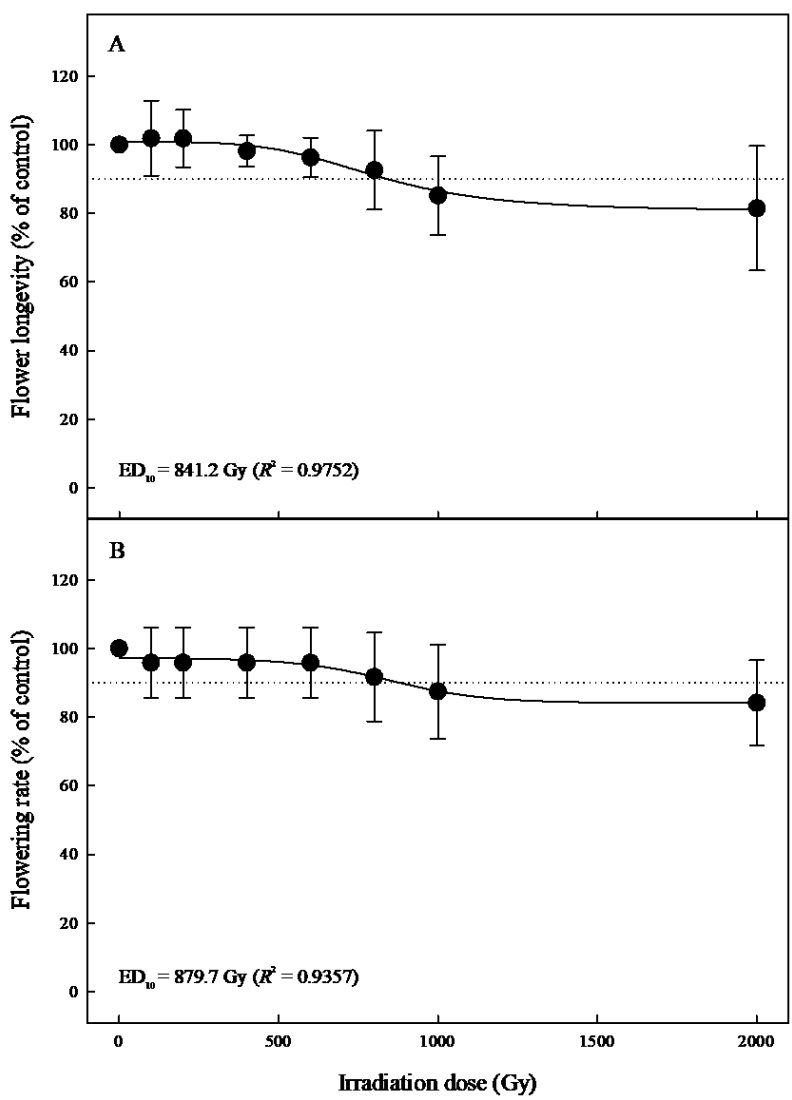

Fig. 5. Dose response curves for electron beam irradiation effects on flower longevity $(A)$ and flowering rate $(B)$ in 'Rosina White' eustomas. Data are the means \pm SD from five replications. 
Plant Protection Convention (IPPC) for postharvest phytosanitary treatments.

\section{Conclusion}

In summary, the current study indicates that 'Montezuma' carnation and 'Rosina White' eustoma may be tolerant to electron beam irradiation at $400 \mathrm{~Gy}$, the generic irradiation dose for postharvest phytosanitary treatments. 'Medusa' lily were highly sensitive to electron beam irradiation even at 200 Gy, we conclude that the 'Medusa' lily is not a good candidate to be treated with irradiation for phytosanitary purpose. Our results show that electron beam irradiation may be available as a phytosanitary treatment without detriment to postharvest quality of cut flowers and $400 \mathrm{~Gy}$ could be a feasible dose for determining the tolerance of cut flowers to electron beam irradiation. Future studies will be required to ascertain the postharvest treatments to reduce the radiation-induced deterioration of cut flowers.

\section{References}

Animal and Plant Health Inspection Service. 2014. Treatment manual. Washington, DC: United States Department of Agriculture.

Chang, A.Y., R.J. Gladon, M.L. Gleason, S.K. Parker, N.H. Agnew, and D.G. Olson. 1997. Postharvest quality of cut roses following electron-beam irradiation. HortScience 32(4):698-701. https://doi.org/10.21273/HORTSCI.32.4.698

Follett, P.A. 2009. Generic radiation quarantine treatments: The next steps. J. Econ. Entomol. 102(4):1399-1406. https://doi.org/10.1603/029.102.0401

Food and Agriculture Organization of the United Nations. 2003. Guidelines for the use of irradiation as a phytosanitary measure. International standards for phytosanitary measures (ISPM No. 18). Rome, Italy: International plant protection convention.

Hallman, G.J. 2012. Generic phytosanitary irradiation treatments. Radiat. Phys. Chem. 81(7):861-866.

Hayashi, T., O.K. Kikuchi, and T. Dohino. 1998. Electron beam disinfestation of cut flowers and their radiation tolerance. Radiat. Phys. Chem. 51(2):175-179. https://doi. org/10.1016/S0969-806X(97)00116-3

Hayashi, T. and S. Todoriki. 1996. Sugars prevent the detrimental effects of gamma irradiation on cut chrysanthemums. HortScience 31(1):117-119. https://doi.org/10.21273/H ORTSCI.31.1.117

Heather, N.W. and G.J. Hallman. 2008. Pest management and phytosanitary trade barriers. Wallingford, UK: CAB International.

Kikuchi, O.K. 2003. Gamma and electron-beam irradiation of cut flowers. Radiat. Phys. Chem. 66(1):77-79. https:// doi.org/10.1016/S0969-806X(02)00264-5

Kim, J.H., T.H. Koo, S.J. Hong, and S.C. Yun. 2014. Application of gamma irradiation and its convergent treatments on several varieties of oriental hybrid lily to control leaf blight. Res. Plant Dis. 20(2):79-86. https://doi. org/10.5423/RPD.2014.20.2.079

Koo, H.N., S.H. Yun, C. Yoon, and G.H. Kim. 2012. Electron beam irradiation induces abnormal development and the stabilization of p53 protein of American serpentine leafminer, Liriomyza trifolii (Burgess). Radiat. Phys. Chem. 81(1):86-92. https://doi.org/10.1016/j.radphyschem.201 1.09 .008

Moon, S.R., B.K. Son, J.O. Yang, J.S. Woo, C. Yoon, and G.H. Kim. 2010. Effect of electron-beam irradiation on development and reproduction of Bemisia tabaci, Myzus persicae, Plutella xylostella, and Tetranychus urticae. Korean J. Appl. Entomol. 49(2):129-137. https://doi.org/ 10.5656/KSAE.2010.49.2.129

Ornelas-Paz, J.J., M.B. Meza, D. Obenland, K. Rodriquez, A. Jain, S. Thornton, and A. Prakash. 2017. Effect of phytosanitary irradiation on the postharvest quality of seedless kishu mandarins (Citrus kinokuni mukakukishu). Food Chem. 230:712-720. https://doi.org/10.1016/j.food chem.2017.02.125

Sangwanangkul, P., P. Saradhuldhat, and R.E. Paull. 2008. Survey of tropical cut flower and foliage responses to irradiation. Postharvest Biol. Technol. 48(2):264-271. https://doi.org/10.1016/j.postharvbio.2007.12.002

van Doorn, W.G. and S.S. Han. 2011. Postharvest quality of cut lily flowers. Postharvest Biol. Technol. 62(1):1-6. https://doi.org/10.1016/j.postharvbio.2011.04.013

Yang, M.S., C.C. Chyau, D.T. Horng, and J.S. Yang. 2002. Effects of irradiation on epidermis ultrastructure of fresh 
day-lily flowers. Radiat. Phys. Chem. 63(3-6):249-251. https://doi.org/10.1016/S0969-806X(01)00508-4

Yun, S.H., S.W. Lee, H.N. Koo, and G.H. Kim. 2014. Assessment of electron beam-induced abnormal devel- opment and DNA damage in Spodoptera litura (F.) (Lepidoptera: Noctuidae). Radiat. Phys. Chem. 96:44-49. https://doi.org/10.1016/j.radphyschem.2013.08.008 